\title{
Relationship between Breakfast and Academic Performance of Primary and Middle School Students in Mianyang City
}

\author{
Xiao Chen ${ }^{1}$, Hongyu Chen'², Linquan Gong1, Yonggen Fang'1, Xiaobing Luo', Dianqing Zhu' ${ }^{1}$ \\ ${ }^{1}$ MianYang Education Research Institution, Mianyang, China \\ ${ }^{2}$ Department of Physical Education, Sichuan University of Science \& Engineering, Zigong, China \\ Email: chenxiao20080529@126.com
}

How to cite this paper: Chen, X., Chen, H.Y., Gong, L.Q., Fang, Y.G., Luo, X.B. and Zhu, D.Q. (2020) Relationship between Breakfast and Academic Performance of Primary and Middle School Students in Mianyang City. Health, 12, 1383-1389.

https://doi.org/10.4236/health.2020.1210100

Received: August 2, 2020

Accepted: October 25, 2020

Published: October 28, 2020

Copyright () 2020 by author(s) and Scientific Research Publishing Inc. This work is licensed under the Creative Commons Attribution International License (CC BY 4.0).

http://creativecommons.org/licenses/by/4.0/

\begin{abstract}
In order to understand the relationship between breakfast frequency and academic performance of grade 5 and grade 8 students, we conducted an investigation through a multistage cluster sampling design with 16,840 students (8017 $5^{\text {th }}$ graders and $88238^{\text {th }}$ graders) from Mianyang city. Results show that: 1) $71.3 \%$ of fifth graders and $59.7 \%$ of eighth graders had breakfast every day of the week, and $9.7 \%$ of fifth graders and $7.5 \%$ of eighth graders had breakfast three times or less per week. 2) The number of times students eat breakfast per week has a significant impact on their comprehensive academic performance, which is reflected in the trend that the more times students eat breakfast, the better their overall academic performance is. Based on this, in order to help students eat breakfast more often, and further improve students' academic performance, we will strengthen the publicity and education of students' breakfast knowledge from multiple perspectives.
\end{abstract}

\section{Keywords}

Breakfast Frequency, Academic Performance, Students, Mianyang City

\section{Introduction}

Primary and secondary school stages are an important period for the formation of students' eating habits, and a key period for students' growth and development. The World Health Organization (WHO) advises that young people should develop a healthy habit of eating breakfast every day. China, the United States, Britain, Japan and other countries have carried out the "plan" for breakfast to ensure that students can eat breakfast every day [1]. Previous research suggests 
that skipping breakfast leads to adverse symptoms in students, such as fatigue, slow reaction and cognitive decline [2], and increases the risk of obesity, hypertension and heart disease [3] [4]. Relevant research also found that compared with those who did not eat breakfast, the brain function activation of those who ate breakfast was more obvious during the task completion [5]. To sum up, breakfast frequency plays an important role on the activation of brain function and on the physiological health of teenagers.

British educator John Locke believed that "all education can be boiled down to the formation of children's good habits". Academic performance is the important basis which evaluates the student knowledge grasp degree, and also is the important index which measures the education effect. Is there a correlation between breakfast frequency and students' academic performance? Studies in cognitive neuroscience have shown that as learning occurs, brain regions associated with cognitive activity such as the parietal, intra-frontal left and right-dorsolateral prefrontal cortex (DLPFC) are activated [4]. In other words, relevant areas of the brain are involved in learning and affect learning efficiency and performance. Relevant studies at home and abroad have found that breakfast frequency is significantly correlated with students' academic performance, and students who eat breakfast have significantly higher academic performance than those who don't eat breakfast [6] [7], and students who ate breakfast every day of the week had significantly higher academic performance than those who did not eat breakfast or ate breakfast less often [8] [9]. To sum up, it can be seen that breakfast frequency affects students' academic performance.

However, survey data and related studies on the physical health of Chinese students over the past decade have found that poor eating habit of primary and secondary school students have become increasingly prominent, forming a vicious cycle of poor eating habit, poor health status and poor academic performance, which hinder development of students [10]. Based on this, this research investigated the breakfast frequency and academic performance of students from grades 5 and 8 in Mianyang city, so as to understand the current situation of breakfast among primary and middle school students, explore the influence of breakfast frequency on the academic performance of students in the city, and provide a theoretical basis for the establishment of good breakfast frequency among primary and middle school students.

\section{Research Design}

\subsection{Participants}

A multi-stage stratified random cluster sampling design was adopted. First, the municipal department shall determine the number of students in each region according to the proportion of primary and junior middle school students of the education statistical data. Secondly, 3 primary schools and 3 junior high schools with high teaching quality were selected to participate in the research, and all the students from 3 classes were randomly selected from the selected schools to par- 
ticipate in the research. Thirdly, after the reference schools are determined, the municipal department will issue documents and organize training, the reference schools will adopt unified instruction language at the same time and in accordance with the same research requirements, and the teacher in charge will conduct the questionnaires collectively after training. After the students complete the questionnaire, the teacher will take back the answer sheet.

In this research, 10,664 students were sent questionnaires in fifth grade.

After eliminating the students with incomplete demographic information (gender information of some students is incomplete due to data matching) and those who did not answer all the questionnaires, a total of 8017 valid questionnaires were collected, with an effective rate of $75.18 \%$, among which 4247 were male students and 3770 were female students. A total of 9952 questionnaires were distributed in the eighth grade, and 8823 valid questionnaires were collected, with an effective recovery rate of $88.66 \%$, including 4549 male students and 4274 female students, excluding students with incomplete demographic information and incomplete answers.

\subsection{Research Content}

The name of the school and the gender of the student are known by using the method of unified data reporting by the school. The questionnaire survey is used to ask the students to answer the questions about "How many times a week do you eat breakfast usually, and five options can be selected", "Three times or less; Four times; Five times; Six times; Seven times".

Comprehensive academic achievement Questionnaire for the fifth grades contains 50 questions on comprehensive knowledge of language, mathematics and other aspects. The maximum score is 100 . The Cronbach's alpha of the questionnaire was 0.90, RMSEA $=0.04$, GFI $=0.98$, AGFI $=0.98$.

Comprehensive academic achievement questionnaire for the eighth grades contains 50 questions on comprehensive knowledge of language, mathematics and other aspects. The maximum score is 100.The Cronbach's alpha of the questionnaire was $0.89, \mathrm{RMSEA}=0.02, \mathrm{GFI}=0.97, \mathrm{AGFI}=0.97$.

\subsection{Data Processing and Analysis}

The valid data was entered into the data base, and SPSS 17.0 and AMOS 17.0 were used for statistical processing.

\section{Research Results}

\subsection{Result of Frequency of Breakfasts}

Frequency analysis shows that $71.3 \%$ of fifth-grade students eat breakfast every week, and 69.8 percent of boys and 72.9 percent of girls eat breakfast every week. $9.7 \%$ of the students had breakfast three times a week or less, among which $10.3 \%$ of the boys had breakfast three times a week or less, and $9 \%$ of the girls had breakfast three times a week or less. See Table 1 for details. 
Table 1. The frequency and proportion of students breakfast per week.

\begin{tabular}{ccccc}
\hline Grade & Breakfast times & Male student & Female student & Total \\
\hline & Three times or less & $437(10.3)$ & $340(9.0)$ & $777(9.7)$ \\
Fifth-grade & Four times & $236(5.6)$ & $179(4.7)$ & $415(5.2)$ \\
student & Five times & $369(8.7)$ & $310(8.2)$ & $679(8.5)$ \\
& Six times & $239(5.6)$ & $193(5.1)$ & $432(5.4)$ \\
& Seven times & $2966(69.8)$ & $2748(72.9)$ & $5714(71.3)$ \\
& Total & 4247 & 3770 & 8017 \\
Eighth-grade & Breakfast times & Male student & Female student & Total \\
student & Three times or less & $350(7.7)$ & $315(7.4)$ & $665(7.5)$ \\
& Four times & $244(5.4)$ & $281(6.6)$ & $525(6.0)$ \\
& Five times & $520(11.4)$ & $552(12.9)$ & $1072(12.2)$ \\
& Six times & $623(13.7)$ & $675(15.8)$ & $1298(14.7)$ \\
& Seven times & $2812(61.8)$ & $2451(57.3)$ & $5263(59.7)$ \\
& Total & 4549 & 4274 & 8823 \\
\hline
\end{tabular}

Frequency analysis shows that $59.7 \%$ of eighth grade students have breakfast every week, among which 61.8 boys and $57.3 \%$ girls have breakfast every week. $7.5 \%$ of the students had breakfast three times a week or less, $7.7 \%$ of the boys had breakfast three times a week or less, and $7.4 \%$ of the girls had breakfast three times a week or less. See Table 1 for details.

Finally, complete content and organizational editing before formatting. Please take note of the following items when proofreading spelling and grammar.

\subsection{Results of Difference Analysis}

In order to analyze the impact of breakfast frequency on comprehensive academic performance, Levene homogeneity test of variance was used to find that the data of grade $5($ Levene $=2.40, \mathrm{p}>0.05)$ and grade $8($ Levene $=2.11, \mathrm{p}>$ 0.05 ) were homogeneity of variance, which could be used for factor analysis.

Taking the number of breakfasts and gender of fifth grade students as independent variables, and the comprehensive academic performance as dependent variables, unilateral difference analysis found that breakfast frequency and gender had significant influence on the comprehensive academic performance of students, and the interaction effect of the number of breakfasts and gender on the comprehensive academic performance of students was not significant. Post-hoc examination found that three times a week and the following four times the number of students breakfast, its comprehensive academic performance there was no significant difference ( $L S D=1.02, \mathrm{p}>0.05$ ), and the rest of the students between different breakfast times, its comprehensive academic achievement all show significant differences, and show the students a week to eat breakfast, the more the better academic performance and the comprehensive academic performance of male students was significantly higher than that of female students $(\mathrm{LSD}=1.03, \mathrm{p}<0.05)$. 
Taking the number of breakfasts and gender of eighth grade students as independent variables and their comprehensive academic performance as dependent variables, unilateral difference analysis found that gender had no significant influence on students' comprehensive academic performance $(F=0.04, p>0.05)$, while the number of breakfasts had a significant influence on students' comprehensive academic performance $(\mathrm{F}=56.77, \mathrm{p}<0.05)$. Post-hoc examination showed that there was no significant difference in comprehensive academic performance between students who had breakfast three times or less per week and those who had breakfast four times per week ( $L S D=-1.23, \mathrm{p}>0.05$ ). There was no significant difference in comprehensive academic performance between students who had breakfast four times a week and those who had breakfast five times a week (LSD $=-1.22, \mathrm{p}>0.05)$. Other students with different breakfast times showed significant differences in their comprehensive academic performance, and the overall trend was that the more students ate breakfast in a week, the better their academic performance. See Table 2 for details.

\section{Discussion}

Overall, the number of students in grade 5 and grade 8 who eat breakfast every week is lower than that in the eastern developed regions. The survey found that $77.5 \%$ of fifth-graders in Beijing and 70.6\% of eighth-graders in Suzhou eat breakfast every day. In comparison, only 71.3 percent of fifth-grade students and 59.7 percent of eighth-grade students have breakfast every day every week, far lower than those in Beijing and Suzhou. Relevant studies have found that the differences in breakfast frequency of students in different regions may be caused by the differences in socioeconomic status. The higher the students' socioeconomic status, the more they ate breakfast each week [11] [12].

The proportion of eighth grade students eating breakfast every day is lower than that of fifth grade students, and the proportion of eighth grade girls eating breakfast every day is lower than that of boys. This is consistent with previous findings [13]. Studies have found that there is cognitive distortion in the body intention of girls in grade 8, and they generally have the tendency of "seeking for thinness" [14]. Combined with the wrong understanding of breakfast, the number of girls who do not eat breakfast is higher than that of boys.

The more often students eat breakfast, the better their academic performance. This is consistent with the conclusions of previous studies [6] [9]. This may be

Table 2. Difference in their comprehensive academic performance analysis result.

\begin{tabular}{|c|c|c|c|c|c|c|}
\hline \multirow{2}{*}{ Grade } & \multicolumn{5}{|c|}{ The number of times a week students eat breakfast } & \multirow{2}{*}{$\mathrm{F}$} \\
\hline & Three times or less & Four times & Five times & Six times & Seven times & \\
\hline Five & $47.29 \pm 13.66$ & $48.06 \pm 13.77$ & $52.00 \pm 13.98$ & $57.08 \pm 14.52$ & $58.86 \pm 13.42$ & $190.95^{\star * *}$ \\
\hline Eight & $55.83 \pm 14.51$ & $57.04 \pm 14.71$ & $58.29 \pm 13.99$ & $63.34 \pm 13.74$ & $61.84 \pm 13.90$ & $56.77^{\star * *}$ \\
\hline
\end{tabular}


because eating breakfast can promote the activation of brain function, and provide supplement energy, protein and vitamin to brain [1], to improve the students' learning efficiency. On the contrary, skipping breakfast makes the brain carry out functional activities only through ketone bodies obtained from the decomposition of fatty acids [5], thus leading to the significant impact of breakfast frequency on students' academic performance.

To sum up, the number of fifth-grade and eighth-grade students who do not eat breakfast is relatively large, and some students may still have problems such as incorrect understanding of. Based on this, further strengthen the publicity and education of breakfast knowledge for teenagers, and carry out breakfast intervention from school, family, society and other perspectives to help students establish a scientific cognitive concept, increase the frequency of students eating breakfast every week, and further improve students' academic performance.

\section{Conflicts of Interest}

The authors declare no conflicts of interest regarding the publication of this paper.

\section{References}

[1] Corcoran, S.P., Elbel, B. and Schwartz, A.E. (2016) The Effect of Breakfast in the Classroom on Obesity and Academic Performance: Evidence from New York City. Journal of Policy Analysis and Management, 35, 509-532. https://doi.org/10.1002/pam.21909

[2] Sakata, K., Matumura, Y., Yoshimura, N., Tamaki, J., Hashimoto, T., Oguri, S., et al. (2001) Relationship between Skipping Breakfast and Cardiovascular Disease Risk Factors in the National Nutrition Survey Data. Nihon Koshu Eisei Zasshi, 48 837-841.

[3] Uzhova, I., Fuster, V., Fernández-Ortiz, A., Ordovás, J.M., Sanz, J., Fernández-Friera, L., et al. (2017) The Importance of Breakfast in Atherosclerosis Disease: Insights from the PESA Study. Journal of the American College of Cardiology, 70, 1833-1842. https://doi.org/10.1016/j.jacc.2017.08.027

[4] Wang, S.S. and Ku, Y.X. (2018) The Causal Role of Right Dorsolateral Prefrontal Cortex in Visual Working Memory. Psychological Bulletin, 7, 727-738. https://doi.org/10.3724/SP.J.1041.2018.00727

[5] Fulford, J., Varley-Campbell, J.L. and Williams, C.A. (2016) The Effect of Breakfast versus No Breakfast on Brain Activity in Adolescents When Performing Cognitive Tasks, as Assessed by fMRI. Nutritional Neuroscience, 19, 110-225.

[6] Rampersaud, G.C., Pereira, M.A., Girard, B.L., Adams, J. and Metzl, J.D. (2005) Breakfast Habits, Nutritional Status, Body Weight, and Academic Performance in Children and Adolescents. American Dietetic Association, 105, 743-760. https://doi.org/10.1016/j.jada.2005.02.007

[7] Hearst, M.O., Jimbo-Llapa, F., Grannon, K., Wang, Q. and Caspi, C.E. (2019) Breakfast Is Brain Food? The Effect on Grade Point Average of a Rural Group Randomized Program to Promote School Breakfast. Journal of School Health, 89, 715-721. https://doi.org/10.1111/josh.12810

[8] Marlatt, K.L., Farbakhsh, K., Dengel, D.R. and Lytle, L.A. (2016) Breakfast and Fast 
Food Consumption Are Associated with Selected Biomarkers in Adolescents. Preventive Medicine Reports, 3, 49-52. https://doi.org/10.1016/j.pmedr.2015.11.014

[9] Jia, Z.H., Wen, X.T., Lin, Y.X., Xu, W.Y., Li, X.Y., Wang, X.Z., Jiang, X.Q., Xie, F. and Yuan, Z.K. (2019) Daily Behavior and Self-Perceived Academic Performance among Students in Jiangxi Province. School of Public Health, 40, 1315-1321.

[10] Zheng, G.G., Ren, J.J., Wang, X.H., et al. (2018) The Correlation of Health Behavior or Habits and Academic Achievement among Middle School Students. Chinese Journal of Social Medical, 35, 49-52.

[11] Shi, Z.M., Pan, X.Q., Dai, Y. and Yuan, B.J. (2007) Analysis of Dietary Behaviors of Middle School Students in Jiangsu Province and Its Social and Economic Influencing Factors. China School Health, 28, 252-253.

[12] Adair, L.S. and Popkin, B.M. (2012) Are Child Eating Patterns Being Transformed Globally? Obesity, 13, 1281-1299. https://doi.org/10.1038/oby.2005.153

[13] Timlin, M.T., Pereira, M.A., Story, M. and Neumark-Sztainer, D. (2008) Breakfast Eating and Weight Change in a 5-Year Prospective Analysis of Adolescents: Project eat (Eating among Teens). Pediatrics, 121, 638-645.

https://doi.org/10.1542/peds.2007-1035

[14] Zhang, L. (2007) Investigation and Analysis of the Current Situation and Causes of Body Image of Adolescent Girls in Kunming City. Doctoral Dissertation, Yunnan Normal University, Kunming. 